\section{Increasing vaccination rates requires a better understanding of vaccine hesitancy}

In their article in CMAJ, Drs. Crowcroft and Bolotin ${ }^{1}$ make a convincing case that systemic change at all levels - from local neighbourhoods to the international stage - will be required in order to achieve the vaccination rates associated with community immunity. They note it is likely that individuals with similar beliefs tend to congregate together, which is why outbreaks, especially of measles, tend to occur among clusters of unvaccinated people.

At the time of this writing (July 19, 2019), Rockland County, New York, has had 282 measles cases during the 20182019 outbreak. Of these individuals, $78.4 \%$ have never received a measles, mumps and rubella (MMR) vaccine. ${ }^{2}$ Although this vaccination rate is not representative of the population at large, it does show that well-reinforced antivaccination ideas are remarkably difficult to change. Crowcroft and Bolotin correctly identify that "a bottom-to-top, systems-level approach is needed to ensure that immunization programs reach every child in every country." 1

Antivaccination sentiments are spreading farther and faster now than any other time in history. It stands to reason that failing to understand the root cause of spreading vaccine hesitancy, using a root-cause analysis, will likely result in efforts to resolve this issue falling short. The reality is that vaccine hesitancy is not a new issue, ${ }^{3}$ and traditional explanations of this movement have not seemed to have done much in the way of reducing its influence. ${ }^{4}$ Crowcroft and Bolotin acknowledge that some groups reject vaccination for various reasons but make no attempt to unpack why.

Addressing some of the underlying issues behind vaccine hesitancy, now called a top 10 global health threat by the World Health Organization (WHO), ${ }^{5}$ would go a long way toward restoring trust and help attain the goals sought by the medical community in general and the authors of this paper in particular.
In a recent paper, Isaac Golden highlights several concerns of the vaccine hesitant. ${ }^{6}$ One major concern is the heavy lobbying of legislators on behalf of large pharmaceutical companies. During the 2013-2014 legislative year in California, pharmaceutical companies gave more than US\$2 million to legislators. This heavy lobbying could lead to a distrust of the industry among the public., ${ }^{6,7}$ Golden also notes that US Food and Drug Administration inspections of clinical trial sites between 2008 and 2013 yielded substantial ethical and safety violations, like safety or informed consent failures in 53\% of studies, and falsification or submission of false information in $39 \%$ of studies. ${ }^{8}$ Trust in pharmaceutical companies is also at historic lows. ${ }^{9}$

In addition to these factors, there are substantial problems in the translational research process that infect the practice of medicine. ${ }^{10}$ Some research has shown that physicians may end up in situations where they are dependent upon drug companies, which may lead to subpar safety testing of drugs. Additionally, researchers "have been found to conduct clinical trials on medications while simultaneously calling for their consumption and guaranteeing that insurance companies will pay for them. Doctors who take such misleading information at face value prescribe drugs that are often unnecessary, harmful to patients, or more costly than equivalent medications." 10

Confusing statements from public health officials have not helped. For example, in a recent article, Dafna Izenberg quotes Crowcroft: "The wonderful thing about the MMR vaccine is you can have as many doses as you like. The risk of getting an adverse effect actually goes down with the number of doses. So the more you [sic] doses you get, the less likely you are to have a side effect." 11 Presumably in response to inquiries about the statement, an addendum was issued to the Izenberg piece on June 14, 2019, which says, "It is extremely safe to receive a second or third dose of the MMR vaccine. In fact, the frequency of adverse events such as fever and rash falls with increas- ing number of doses of live vaccines because once antibodies have been developed, they prevent replication of the attenuated vaccine virus (whether measles, mumps, rubella, or other vaccine)."11

But fever and rash are likely not the motivations behind vaccine hesitancy. The above exchange did not make clear whether increased MMR uptake results in an increase in more serious adverse reactions like encephalopathy, seizures or anaphylaxis as described in the WHO vaccine safety information sheet offered in defence of the addendum. ${ }^{12}$ To Izenberg and Crowcroft's credit, both the addendum and the information sheet do address the reason why fever and rash are likely to decrease after a second or third MMR, but a second study cited in defence of the addendum monitored adverse effects in these trials for only 2 weeks. The abstract for the latter study concludes thusly: "to assess risk for rare or serious [adverse events] after a third dose of MMR vaccine, longer term studies would be required." 13

Another abstract is cited in the addendum to the Izenberg article. A team studied the safety profiles of the MMR and measles, mumps, rubella and varicella (MMRV) vaccines in Ontario's publicly funded program from 2012 to 2016. The abstract states that there were 289 adverse events between the MMR group and the MMRV group. According to the terms of the study, "a serious AEFI [adverse event following immunization] is defined as an AEFI that resulted in an inpatient hospitalization or death." Annualized reporting rates for MMR work out to 16.6 per $100000(0.016 \%)$ and 8.8 per $100000(0.008 \%)$ for MMRV. Finally, 22 serious AEFIs were recorded: 19 from MMR and 3 from MMRV (1.3 and 0.6 per 100000 doses, respectively). Of adverse reactions, $7.6 \%$ (22 of 289 ) resulted in admission to hospital or death. The abstract concludes that no safety concerns were identified, seemingly because the safety profile is consistent with other findings. ${ }^{14}$ But it is hard to overlook that while a serious AEFI rate of 1.3 per 100000 sounds low, the fact that millions of children get an MMR each year makes some 
instances of hospital admission and death a mathematical certainty. Therefore, this addendum was not helpful in the way of answering the question of whether there are data that show a decrease in serious adverse events positively correlating with an increase in MMR use. Furthermore, at least 1 study intended to defend the proposition that repeated MMR vaccination results in fewer adverse effects seems to imply that the matter was not studied because the trials lasted only 2 weeks. ${ }^{13}$ Counterintuitive statements of this nature, especially by public health authorities, tend to leave behind more questions than answers. Neither in the CMAJ commentary nor in Izenberg's article is there any discussion of more serious adverse reactions associated with the vaccine. ${ }^{15}$

Crowcroft and Bolotin are spot on when they say that "in the war against microbes, victories are achieved at a huge price, and the peace that follows is tragic." If the elimination of 1 or 2 pathogens (out of hundreds that can kill a person) brings with it a serious loss of public trust, how will future progress continue? It will be impossible to maintain herd immunity in this environment.

It will be impossible to attain the topto-bottom, systemic transformation the authors desire without a better dialogue regarding vaccine hesitancy. Without this, public trust in vaccination will continue to decline. I believe that the single best way for governments and public health organizations to improve public trust and therefore increase vaccination rates is to monitor for adverse reactions for longer than 6 weeks in clinical trials and report adverse reactions to someone other than the drug manufacturer before licensure. ${ }^{16}$ This will require policy adjustments commensurate with study results, but seeking to address vaccine hesitancy without addressing the concerns of the vaccine hesitant is a self-defeating enterprise.

\section{Joshua P. Bennett MA NHA}

Health center administrator, Presbyterian Senior Living, Byron, Ill.

- Cite as: CMAJ 2019 October 21;191: E1167-8. doi: $10.1503 / \mathrm{cmaj} .73258$

\section{References}

1. Crowcroft NS, Bolotin S. Measles outbreaks demand systems-level action locally, nationally and globally. CMAJ 2019;191:E777-8.

2. Measles information: 2018-2019 measles outbreak in Rockland County. New York: Rockland County. Available: http://rocklandgov.com/departments/ health/measles-information/ (accessed 2019 July 19).

3. Poland GA, Jacobson RM. The age-old struggle against the antivaccinationists. N Engl J Med 2011;364:97-9.

4. Understanding the Anti-Vaxxer movement. North Sydney (AU): University of South Australia. Available: https://unisa.edu.au/Research/institute-for -choice/Our-Research/Understanding-the-Anti -Vaxxer-Movement/ (accessed 2019 July 19).

5. Ten threats to global health in 2019. Geneva: World Health Organization; 2019. Available: www. who.int/emergencies/ten-threats-to-global-health -in-2019 (accessed 2019 July 19).

6. Golden I. Reluctance to vaccinate: reasons and solutions. J Trans/ Sci 2019;5:1-6. doi: 10.15761/ JTS. 1000326.

7. Sarich C. Drug companies donated millions to California lawmakers prior to forced vaccination bill: Should we not have the right to choose? Montréal: Centre for Research on Globalization; 2015 June 22. Available: www.globalresearch.ca/drug-companies -donated-millions-to-california-lawmakers-prior-to -forced-vaccination-bill/5457393 (accessed 2019 July 19).
8. Seife C. Research misconduct identified by the US Food and Drug Administration: out of sight, out of mind, out of the peer-reviewed literature. JAMA Intern Med 2015;175:567-77.

9. Barry K. Vaccine Whistleblower: exposing autism research fraud at the CDC. New York: Skyhorse Publishing; 2015.

10. JLME issue on institutional corruption and the pharmaceutical industry. Cambridge (MA): Edmond J. Safra Center for Ethics, Harvard University; 2013 Sept. 30. Available: https://ethics.harvard.edu/news/jlme -issue-institutional-corruption-and-pharmaceutical -industry (accessed 2019 July 19).

11. Izenberg D. Measles: who is at risk and what can they do. Toronto: La Ki Shing Knowledge Institute, St. Michael's Hospital; 2019 Mar. 7. Available: https://healthydebate.ca/2019/03/topic/ measles-who-is-at-risk (accessed 2019 July 19).

12. Observed rate of vaccine reactions: measles, mumps, and rubella vaccines [information sheet] Geneva: World Health Organization; May 2014. Available: www.who.int/vaccine_safety/initiative/ tools/MMR_vaccine_rates_information_sheet.pdf (accessed 2019 July 19).

13. Abedi GR, Mutuc JD, Lawler J, et al. Adverse events following a third dose of measles, mumps, and rubella vaccine in a mumps outbreak. Vaccine 2012;30:7052-8.

14. Seo CY, Rashid M, Harris T, et al. Assessing safety of Ontario's publicly funded MMR and MMRV immunization programs, 2012 to 2016. Paediatr Child Health. 2019 Apr. 8 [Epub ahead of print]. doi: 10.1093/pch/pxz037.

15. MMRII (Measles, Mumps, and Rubella Virus Vaccine Live. Rockville (MD): US Food and Drug Administration: 6-8. Available: www.fda.gov/ media/75191/download (accessed 2019 July 19).

16. Summary No. 1 of clinical investigative studies of combined live measles virus vaccine (Moraten Line-ATTENUVAX), Jeryl Lynn mumps virus vaccine (MUMPSVAX), RA 27/3 rubella virus vaccine: for purpose of support for a license to manufacture and sell. Peachtree City (GA): Children's Health Defense; 1978; 8-11 for study methodology. Available: https://childrenshealthdefense.org/wp-content/ uploads/FDA-Relied-Upon-STUDIES-LICENSING -MMR-VACCINE-FOIA.pdf (accessed 2019 July 19).

Competing interests: None declared.

Disclaimer: This letter is the author's perspective alone and does not represent the opinion of Presbyterian Senior Living. 